\title{
No evidence for a bone phenotype in GPRC6A knockout mice under normal physiological conditions
}

\author{
Petrine Wellendorph, Lars Dan Johansen, Anders A Jensen, Emilio Casanova ${ }^{1 \dagger}$, \\ Martin Gassmann ${ }^{1}$, Pierre Deprez ${ }^{2}$, Philippe Clément-Lacroix ${ }^{2}$, Bernhard Bettler ${ }^{1}$ \\ and Hans Bräuner-Osborne \\ Department of Medicinal Chemistry, Faculty of Pharmaceutical Sciences, University of Copenhagen, Universitetsparken 2, DK-2100 Copenhagen, Denmark \\ ${ }^{1}$ Department of Biomedicine, Institute of Physiology, University of Basel, Klingelbergstrasse 50, $\mathrm{CH}-4056$ Basel, Switzerland \\ ${ }^{2}$ Galapagos, 60 Avenue Gaston Roussel, F-93230 Romainville, France \\ (Correspondence should be addressed to P Wellendorph; Email: pw@ farma.ku.dk) \\ ${ }^{\dagger}$ (E Casanova is now at Ludwig Boltzmann Institute for Cancer Research (LBI-CR), Währinger Strasse 13a, A-1090 Vienna, Austria)
}

\begin{abstract}
GPRC6A is a seven-transmembrane receptor mediating signaling by a wide range of $L$ - $\alpha$-amino acids, a signaling augmented by the divalent cations $\mathrm{Ca}^{2+}$ and $\mathrm{Mg}^{2+}$. GPRC6A transcripts are detected in numerous mammalian tissues, but the physiological role of the receptor is thus far elusive. Analogously to the closely related calcium-sensing receptor, GPRC6A has been proposed to function as a metabolic sensor of $\mathrm{Ca}^{2+}$ and amino acids in bone and other tissues. In the present study, we have generated the first GPRC6A knockout mice and studied their phenotype with particular focus on bone homeostasis. The generated GPRC6A knockout mice are viable and fertile, develop normally, and exhibit no significant differences in body weight compared with wild-type littermates. Assessment of bone mineral density, histomorphometry, and bone metabolism demonstrated no significant differences between 13-week-old knockout and wild-type mice. In conclusion, our data do not support a role for GPRC6A in normal bone physiology.
\end{abstract}

Journal of Molecular Endocrinology (2009) 42, 215-223

\section{Introduction}

The ' $\mathrm{G}$ protein-coupled receptor family $\mathrm{C}$ subtype $6 \mathrm{~A}$ ', GPRC6A, is the most recently identified member of family $\mathrm{C}$ in the superfamily of seven-transmembrane (7TM) receptors, also termed $\mathrm{G}$ protein-coupled receptors. Family $\mathrm{C}$ mammalian receptors also include the metabotropic glutamate (mGlu), $\gamma$-aminobutyric $\operatorname{acid}_{\mathrm{B}}\left(\mathrm{GABA}_{\mathrm{B}}\right)$, T1R taste and calcium-sensing receptors. Aside from the 7TM domain governing $\mathrm{G}$ protein activation, family $\mathrm{C}$ receptors also possess a large amino-terminal domain containing the orthosteric binding site (Pin et al. 2003, 2004).

To date, the in vivo functions of GPRC6A have not been investigated, and the physiological importance of the receptor is thus unknown. Cloning and pharmacological characterization of human, mouse, and rat GPRC6A orthologues have found the receptor to be stereoselectively activated by natural $\mathrm{L}-\alpha$-amino acids, preferentially basic amino acids L-arginine, L-lysine, and L-ornithine, but also small and polar amino acids (Wellendorph \& Bräuner-Osborne 2004, Kuang et al. 2005, Wellendorph et al. 2005, 2007, Christiansen et al. $2006 a, b)$. Sensitivity to such a broad range of amino acids could possibly reflect the physiological role of the receptor (Conigrave \& Hampson 2006, Bräuner-Osborne et al. 2007, Conigrave et al. 2008). Using heterologous expression systems, we and others have additionally found that the L- $\alpha$-amino acid response of GPRC6A is augmented by the presence of divalent cations $\mathrm{Ca}^{2+}$ and $\mathrm{Mg}^{2+}$ in physiologically relevant concentrations (Kuang et al. 2005, Christiansen et al. 2007, Wellendorph et al. 2007). Quarles and co-workers have reported the mouse GPRC6A (mGPRC6A) to be directly activated by high concentrations of $\mathrm{Ca}^{2+}$ in the absence of $\mathrm{L}-\alpha-$ amino acids (Pi et al. 2005). Regardless of whether $\mathrm{Ca}^{2+}$ is a direct agonist or a potentiator of GPRC6A signaling, the concomitant binding of amino acids and $\mathrm{Ca}^{2+}$ appears to be a general characteristic of family $\mathrm{C}$ receptors. The orthosteric binding sites of family $\mathrm{C}$ receptors are highly conserved (Silve et al. 2005, Kuang et al. 2006) and also mGlu and $\mathrm{GABA}_{\mathrm{B}}$ receptor signaling has been shown to be allosterically modulated by $\mathrm{Ca}^{2+}$ (Kubo et al. 1998, Saunders et al. 1998, Wise et al. 1999, Conigrave et al. 2000, Galvez et al. 2000, Francesconi \& Duvoisin 2004).

GPRC6A exhibits a remarkable similarity to the calcium-sensing receptor (CaR) with regard to phylogeny, genomic organization, wide expression in tissues and organs, and ligand preferences. As inferred from 
phylogenetic analyses of human family $\mathrm{C}$ receptors, GPRC6A has the highest overall amino acid sequence identity with CaR (45\% overall amino acid identity) and vice versa (Kuang et al. 2005). Moreover, GPRC6A, $\mathrm{CaR}$, and taste receptors (T1R), all of which respond to amino acids in a broad sense, appear to form a distinct subgroup of family $\mathrm{C}$ receptors (Bjarnadóttir et al. 2005, Kuang et al. 2006). The organization of the genes for GPRC6A and CaR is strikingly similar, each being composed of six protein-coding exons with intervening introns. In Casr, exon 1A/1B codes alternative $5^{\prime}$-untranslated regions (Chikatsu et al. 2000). The last exon in each receptor (exon VI in Gprc6a and exon VII in Casr) encodes the entire 7TM domain and C-terminus (Kuang et al. 2005). The widespread tissue expression of GPRC6A is also reminiscent of CaR (Mitsuma et al. 1999). Whereas $\mathrm{CaR}$ is activated by $\mathrm{Ca}^{2+}$ and $\mathrm{Mg}^{2+}$ and positively modulated by L- $\alpha$-amino acids (Conigrave et al. 2000, Zhang et al. 2002), GPRC6A appears to function in a reciprocal fashion (Christiansen et al. 2007).

The ability of GPRC6A to respond to numerous amino acids and divalent cations, the close relationship with $\mathrm{CaR}$, and the expression in major organs and tissues including heart, lung, kidney, liver, pancreas, skeletal muscle, and brain (Wellendorph \& BräunerOsborne 2004, Kuang et al. 2005) has spurred several suggestions for the physiological context of GPRC6A. The receptor has been proposed to be involved in the regulation of the urea cycle, in sensing of $\mathrm{Ca}^{2+}$ and amino acids in the blood, in neurotransmission (Wellendorph et al. 2005, Bräuner-Osborne et al. 2007), and in the monitoring of cell death (Civelli 2005). The findings of more recent studies suggest additional putative physiological roles of the receptor, as GPRC6A transcripts have been demonstrated in specialized tissues such as bone and cultured osteoblasts ( $\mathrm{Pi}$ et al. 2005), pancreatic islets (Regard et al. 2007), taste tissue (Wellendorph et al. 2007), and on the protein level in mesenteric arteries (Harno et al. 2008).

The functions maintained by GPRC6A are obviously of particular interest in tissues where $\mathrm{L}-\alpha$-amino acids and/or $\mathrm{Ca}^{2+}$ are known to play important physiological roles. Based on the expression of GPRC6A in long bone, calvarias, and cultured osteoblasts, $\mathrm{G} \alpha_{\mathrm{i}} / \mathrm{G} \alpha_{\mathrm{q}}$-mediated signaling in response to divalent and trivalent cations, and modulation of the signaling by the calcimimetic NPS R-568 and osteocalcin, Quarles and co-workers have proposed mGPRC6A to be an important receptor in bone (Pi et al. 2005). Also, considering the role of $\mathrm{Ca}^{2+}$ and L-amino acids in bone homeostasis and formation, this is a relevant hypothesis to address (Teitelbaum 2000, Dvorak \& Riccardi 2004, Breitwieser 2008, Conigrave et al. 2008). Investigations into the in vivo functions of GPRC6A are, however, complicated by the absence of high-affinity ligands selectively targeting the receptor.
To overcome this problem and investigate the function of this receptor, we have generated a GPRC6A knockout mouse, and here for the first time report studies on phenotypic parameters with particular focus on normal bone physiology.

\section{Materials and methods}

\section{Design and cloning of targeting vector}

For the targeted disruption of Gprc6a, exon VI, containing the entire 7TM domain and C-terminal tail of the gene, was deleted using the cyclization recombination at a locus of $x$-over of the bacteriophage $P 1 \quad(\mathrm{CRE}-$ Loxp) and the yeast FLiPpase recombinase target (FLP-Frt) systems by a 2-Loxp-2-Frt strategy (Kwan 2002, Tronche et al. 2002) as outlined in Fig. 1 and detailed in the Supplementary material, see Supplementary data in the online version of the Journal of Molecular Endocrinology at http://jme.endocrinologyjournals.org/content/vol42/issue3/.

\section{Homologous recombination and generation of GPRC6A $^{-\prime-}$ mice}

GPRC6A $^{-/-}$mice were generated by homologous gene targeting in E14.1 embryonic stem (ES) cells (129P2/OlaHsd) as detailed in Supplementary material. Southern blot analysis using $5^{\prime}$ and $3^{\prime}$-located hybridization probes derived from genomic sequences located outside the regions of homology was used to assess whether homologous recombination (HR) had occurred and a correctly targeted Gprc6a allele had been generated (Fig. 1A and C).

High-percentage chimeric females were mated with C57BL/6 males looking for germline transmission. The presence of a Loxp-flanked (floxed) allele was confirmed by PCR analysis for Neo using the specific primers (Fneo: $5^{\prime}$-aacaagatggattgcacgc- $3^{\prime}$ and Rneo: $5^{\prime}$ aagaactcgtcaagaagg- $3^{\prime}$ ). To create a full knockout, males heterozygous for the $N e o^{r}$-targeted, floxed allele were mated to ubiquitously expressing C57BL/6 CRE-deleter females to obtain GPRC6A ${ }^{+/-C r e+}$ offspring (Schwenk et al. 1995). These were backcrossed into the C57BL/6 background to remove Cre and to produce a genetically pure offspring. For the current studies, the Cre-lacking heterozygotes were intercrossed to create littermates of all three genotypes $\left({ }^{+/+},{ }^{+/-}\right.$, and $\left.{ }^{-/-}\right)$.

\section{Genotyping}

Genotyping of mice after Cre deletion was analyzed by PCR using gDNA extracted from tails of the mice. For the PCR, a primer located in exon VI (P1: 
A

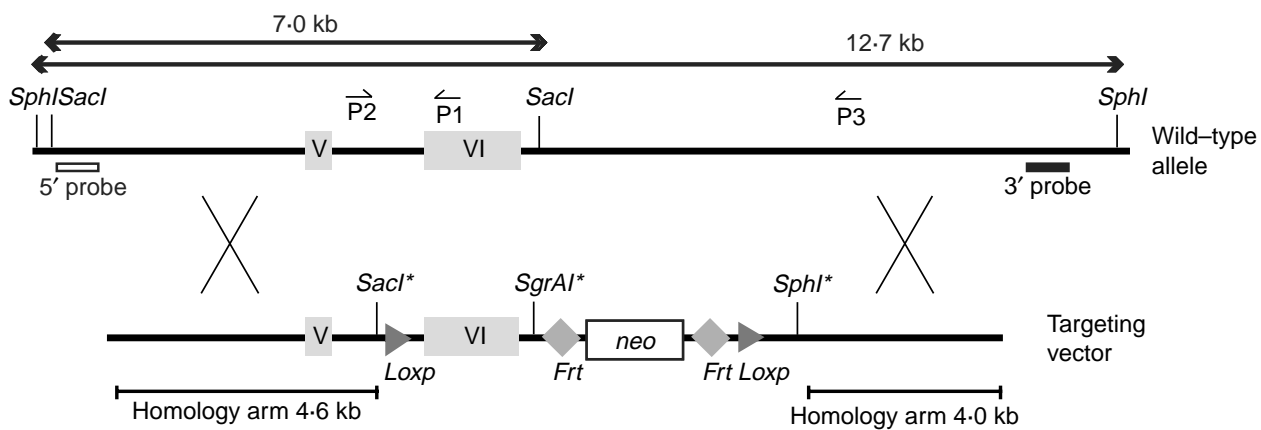

B

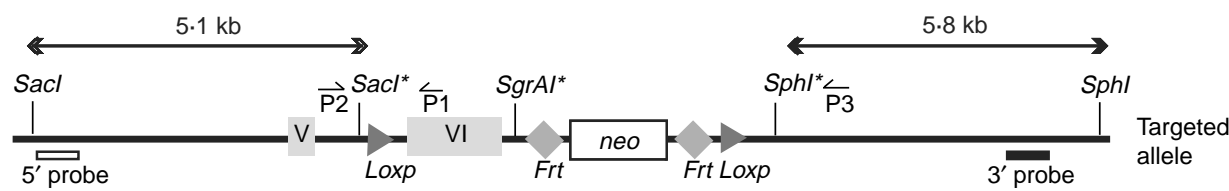

C

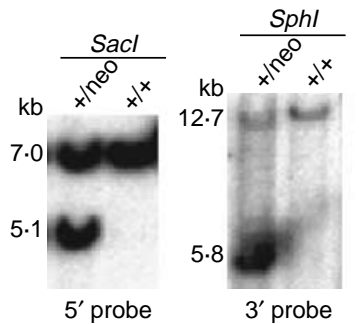

D

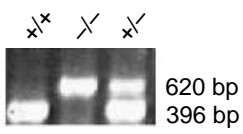

$\mathrm{E}$

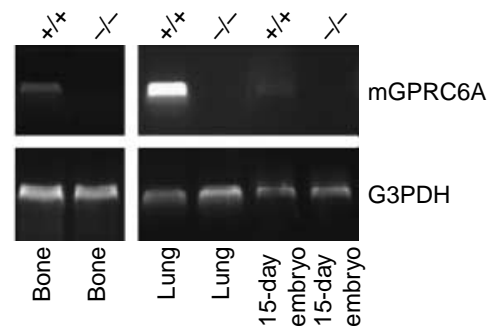

Figure 1 Targeted disruption of the mouse Gprc6a gene and its molecular analysis. (A) Targeting strategy used for the deletion of the Gprc6a exon VI. Partial scheme of the Gprc6a wild-type allele, at the top depicting exons $\mathrm{V}$ and $\mathrm{VI}$, the intervening intron $\mathrm{V}$, and inherent restriction enzyme recognition sites used for Southern analysis. Fragments used for Southern analysis are denoted as $5^{\prime}$ and $3^{\prime}$ probes. The targeting vector is shown below the wild-type allele showing the 2-Loxp-2-Frt design, the homology arms, and the site-directed engineered restriction enzyme sites marked by asterisks. (B) The correctly targeted Gprc6 $a^{\text {neo }}$ allele resulting from HR in ES cells. Indicated is the Southern analysis strategy and expected band sizes. (C) Southern analysis. Shown is a representative blot of screening for HR events in ES cells. To the left, DNA was digested with Sacl and the $5^{\prime}$ probe used. Wild-type $(+)$ and $\mathrm{NeO}^{r}$-targeted, floxed alleles (neo) are represented by DNA fragments of $7 \cdot 0$ and $5 \cdot 1 \mathrm{~kb}$ respectively. To the right, DNA was digested with Sphl and the $3^{\prime}$ probe used. Wild-type $(+)$ and targeted (neo) alleles are represented by DNA fragments of $12 \cdot 7$ and $5.8 \mathrm{~kb}$ respectively. (D) PCR genotyping. Example of a typical PCR of GPRC6A ${ }^{+/+}$, ${ }_{-1-}$, and ${ }^{+1-}$ mice. Primers $\mathrm{P} 1$ and $\mathrm{P} 2$ yield a 396 bp product $((+)$ allele) and primers $\mathrm{P} 2$ and $\mathrm{P} 3$ yield a $620 \mathrm{bp}$ product $((-)$ allele). (E) RT-PCR products of expected sizes (698 bp; primers P4 and P5) were detected readily with GPRC6A ${ }^{+1+}$ but not with GPRC6A ${ }^{-1-}$ bone, lung, and 15-day embryo cDNA as template (bone tissue was analyzed in a separate PCR run). G3PDH gave consistent (982 bp) bands in all tissues examined. Only the shown bands were detected.

5'-CAGGTAGTGCTCCTTACTG-3') was used together with a primer located in intron $\mathrm{V}$ upstream of the first Loxp site (P2: 5'-GGAGATGGCCTTGAGCTATGTG-3'), a combination that amplified a $396 \mathrm{bp}$ band from the wild-type allele and a $474 \mathrm{bp}$ band from the floxed allele, whereas no band was amplified from the deleted allele. A primer located in the $3^{\prime}$ homology arm (P3 5'-CAGTGATCACTCAGCCAGACAC-3') was used together with P2 to amplify a $620 \mathrm{bp}$ band from the deleted allele. For routine genotyping, a PCR protocol employing a mixture of $\mathrm{P} 1, \mathrm{P} 2$, and $\mathrm{P} 3$ was used $\left(94^{\circ} \mathrm{C}\right.$ $2 \mathrm{~min}$ initial, then $94{ }^{\circ} \mathrm{C} 1 \mathrm{~min}$, annealing at $55^{\circ} \mathrm{C}$ for $1 \mathrm{~min}$ and extension at $72^{\circ} \mathrm{C}$ for 1 min for 35 cycles) to generate fragments of $396 \mathrm{bp}$ for the $(+)$ allele and $620 \mathrm{bp}$ for the $(-)$ allele (Fig. 1D).

\section{RT-PCR analysis}

Lung and femur tissue from 17- to 19-week-old GPRC6A $^{+/+}$and ${ }^{-/-}$male mice and 15-day-old 
GPRC6A $^{+/+}$and ${ }^{-/-}$embryos were isolated, preserved in pulverized dry ice and stored at $-80^{\circ} \mathrm{C}$ until further processing. The femur was pulverized in liquid nitrogen using a mortar and pestle and total RNA was extracted with RNeasy Lipid Tissue Mini Kit (Qiagen), whereas total RNA from lung and embryos was extracted using RNeasy Mini Kit (Qiagen). Total RNA was used for firststrand cDNA synthesis (QuantiTect Reverse Transcription Kit, Qiagen), according to the protocols of the manufacturer. Intron V-spanning primers specific for exons V (P4: $5^{\prime}$-gccetggtcaaatgaagaaa-3') and VI (P5: $5^{\prime}$-tgatgtagcccagcatggta- $\left.3^{\prime}\right)$ were used for the RT-PCR using an optimized PCR protocol $\left(94^{\circ} \mathrm{C} 5\right.$ min predenaturation, then $94^{\circ} \mathrm{C} 30 \mathrm{~s}$, annealing at $57^{\circ} \mathrm{C}$ for $30 \mathrm{~s}$ and extension at $72^{\circ} \mathrm{C}$ for $1 \mathrm{~min} 20 \mathrm{~s}$ for 45 cycles). RT-PCR products were separated on $1 \% \mathrm{w} / \mathrm{v}$ agarose gels and detected with SYBR Safe (Invitrogen).

\section{Animal care}

Animals were maintained and bred in a commercial pathogen-free facility (Taconic, Silkeborg, Denmark). In general, mice were housed in a climate-controlled animal facility $\left(25^{\circ} \mathrm{C}, 55-60 \%\right.$ humidity, $12 \mathrm{~h}$ light: $12 \mathrm{~h}$ darkness cycle) and had free access to food and water. For analysis of body weight, eight GPRC6A wild-type and knockout mice of each gender were weighed every week from week 6 to 16 , and every 2 weeks from week 18 to 38. Animal experiments for bone phenotyping were carried out in accordance with the European Communities Council Resolves of 24 November 1986 (86/609/ECC) and approved by the Danish Animal Experiments Inspectorate (J. No. 2006/561-1232).

\section{Bone structural histology}

The tibias were recovered from 13-week-old mice following killing and analyzed by tomodensitometry, histomorphometry, and densitometry. For tomodensitometry analysis, the right tibias were fixed overnight in $4 \% \mathrm{w} / \mathrm{v}$ formaldehyde in PBS, washed with PBS, and then stored in $70 \% \mathrm{v} / \mathrm{v}$ ethanol. Micro-computerized tomography $(\mu \mathrm{CT})$ scans of the metaphyseal region were performed at an isotropic resolution of $9 \mu \mathrm{m}$, to obtain trabecular bone structural parameters. Using a two- and three-dimensional (3D) model and a semiautomatic contouring algorithm, we determined 3D bone volume, bone surface, and the trabecular thickness. 3D images were obtained on a Scanco Medical $\mu$ CT scanner ( $\mu$ CT 20; Scanco Medical AG, Bassersdorf, Switzerland). A total of 450 images were obtained from each bone sample using a $512 \times 512$ matrix, resulting in an isotropic voxel resolution of $18 \times 18 \times 18 \mu^{3}$. Measurements were stored in 3D image arrays with an isotropic voxel size of $9 \mu \mathrm{m}$.
A constrained 3D Gaussian filter was used to partly suppress the noise in the volumes. The bone tissue was segmented from bone marrow using a global thresholding procedure. In addition to the visual assessment of structural images, morphometric indices were determined from the microtomographic data sets. Cortical and trabecular bone were separated using a semi-automated contour-tracking algorithm to detect the outer and inner boundaries of the cortex. In trabecular bone, basic structural metrics were measured using direct 3D morphometry (Rüegsegger et al. 1996, Kapadia $e t$ al. 1998). The images were also rendered for 3D display and visualization.

\section{Bone densitometry}

The left tibia was used for densitometric analysis with the Stratec peripheral quantitative computerized tomography (pQCT) XCT Research SA+ (version 5.4B; Norland Medical Systems, White Plains, NY, USA) at $70 \mu \mathrm{m}$ resolution. Trabecular volumetric bone mineral density (BMD) was measured by metaphyseal pQCT scans positioned $1 \mathrm{~mm}$ from the distal growth plate and corresponding to $6 \%$ of the total length of the tibia. The trabecular region was defined as an inner area of $60 \%$ of the total cross-sectional area (Sims et al. 2003). Diaphyseal tibia cortical BMD was measured by pQCT scans positioned at $7 \mathrm{~mm}$ from the distal growth plate and corresponding to $42 \%$ of the total length of the tibia. Specific mode of analysis (peel 2) was used to calculate cortical density. The default algorithm removes voxels within the trabecular part that have an attenuation coefficient below the threshold of $710 \mathrm{mg} / \mathrm{cm}^{3}$. The inter-assay coefficients of variation $(\mathrm{CV})$ for the pQCT measurements were $<2 \%$.

\section{Bone biomarkers}

For osteocalcin level measurements, blood was collected in tubes containing coagulation activator on the day of killing. Plasma and serum samples were separated by centrifugation at 3000 r.p.m. $(750 \mathrm{~g})$ for $20 \mathrm{~min}$ at room temperature and serum was stored at $-20{ }^{\circ} \mathrm{C}$ until the analysis was performed. All assays were performed in duplicate. Serum osteocalcin was assayed with kits and reagents from Biomedical Technologies Inc. (Stoughton, MA, USA), as described previously (Clément-Lacroix et al. 2000). The intra- and inter-assay CVs were $2 \cdot 0-2 \cdot 3 \%$ and $4 \cdot 0-5 \cdot 0 \%$ respectively. At 11 weeks of age, urine was collected overnight in singlehousing metabolic cages and stored at $-20^{\circ} \mathrm{C}$. Urinary deoxypyridinoline cross-link levels (D-Pyr) were measured using a colorimetric assay from Pacific Biometrics Inc. (Tampa, FL, USA), and normalized to 
creatinine concentration (measured by Metra creatinine assay kit (QUIDEL, San Diego, CA, USA)) to correct for water excretion as described by Sims $e t$ al. (2003). The intra- and inter-assay CVs were $3 \cdot 1-4 \cdot 8 \%$ and $4 \cdot 3-8 \cdot 4 \%$, respectively.

\section{Statistical analyses}

Data were expressed as mean \pm s.E.M. Statistical differences were calculated using Student's $t$-test or ANOVA for multiple comparisons. $P<0.05$ were considered statistically significant.

\section{Results}

\section{Generation of GPRC6A-deficient C57BL/6 mice}

By analogy to the human GPRC6A gene, the mouse orthologue is encoded by six exons, which span approximately $16 \mathrm{~kb}$ of genomic DNA (Kuang et al. 2005). For the purpose of generating GPRC6A-deficient $\left(\mathrm{GPRC6A}^{-/-}\right)$mice by HR in ES cells, we targeted exon VI using the site-specific CRE-Loxp recombinase technology (Kilby et al. 1993, Tronche et al. 2002). Exon VI encodes 1113 nuc and encompasses the entire 7TM domain and C-terminal of the receptor, as well as 42 nuc of the $3^{\prime}$ UTR. The inserts were placed in regions that would not interfere with normal expression of the gene. The upstream LoxP was placed 300 nuc upstream of exon VI and the other inserts 300 nuc downstream of the predicted polyadenylation site. As the targeting strategy will result in the deletion of the regions of mGPRC6A involved in $\mathrm{G}$ protein-coupling and other putative intracellular signaling mechanisms elicited by the receptor, presumably the expression and/or folding of the amino-terminal domain of mGPRC6A will also be disrupted. A similar strategy of floxing the corresponding exon VII in Casr has proven efficient for the generation of conditional Casr knockout mice (Chang et al. 2008). To enable the future generation of a conditionally mutated allele, the $\mathrm{Neo}^{r}$ gene was additionally flanked by Frt sites (Fig. 1A). However, in the present study only full knockouts were generated, using CRE-Loxp recombination.

Correct targeting and incorporation of the targeted allele into ES cells (Fig. 1B) was confirmed by Southern blot analysis (Fig. 1C). Following restriction digestion using $S a c \mathrm{I}$, the $5^{\prime}$ probe (a $0 \cdot 82 \mathrm{~kb} S a c \mathrm{I} /$ SpeI fragment) detected a $7 \cdot 0 \mathrm{~kb}$ fragment for the wild-type allele and an extra fragment of $5 \cdot 1 \mathrm{~kb}$ corresponding to the mutant allele (Fig. 1C, left). Correspondingly, following restriction digestion using $S p h \mathrm{I}$, the $3^{\prime}$ probe $($ a $0.54 \mathrm{~kb}$ SacII-fragment) detected a $12.7 \mathrm{~kb}$ fragment for the wild-type allele and an extra fragment of $5.8 \mathrm{~kb}$ for the mutant allele (Fig. 1C, right). Experiments using an internal probe (a $0.76 \mathrm{~kb} S a c \mathrm{I} / \mathrm{BamH \textrm {I }}$ fragment) verified that multiple integrations into the Gprc6a locus had not occurred (data not shown).

Targeted ES cells were used to generate germlinetransmitting chimeras, which were mated to C57BL/6 mice to generate heterozygote offspring containing the $\mathrm{Neo}{ }^{r}$ gene $\left(\mathrm{Gprc} \mathrm{a}^{n e o}\right)$. GPRC6A ${ }^{+}{ }^{-}$mice were generated by crossing Gprc6a ${ }^{\text {neo }}$ with a ubiquitously expressing CRE-deleter mouse (Schwenk et al. 1995) and backcrossing into the C57BL/ 6 background. Genotyping was performed by PCR (Fig. 1D).

\section{Confirmation of generation of GPRC6A knockout mice at the mRNA level}

To confirm that the knockout strategy had led to deletion of the GPRC6A gene product, RT-PCR was performed (Fig. 1E). To this end, we designed intronspanning primers located at exons V and VI in order to avoid contamination from genomic DNA. As expected, bands were detected in wild-type tissues reported to express GPRC6A mRNA (bone, lung and 15-day embryo; Kuang et al. 2005, Pi et al. 2005, Wellendorph et al. 2005) and GPRC6A protein (15-day embryo; Kuang et al. 2005). By contrast, no expression of mGPRC6A was observed in the same tissues from GPRC6A $^{-/-}$littermates, thus confirming the absence of GPRC6A mRNA in these mice.

\section{Initial phenotypic characterization}

Mice lacking either one or both Gprc6a alleles were viable and born at expected Mendelian frequencies. The mice developed normally, were fertile, and exhibited no obvious behavioral or physical phenotype. Furthermore, neither female nor male GPRC6A ${ }^{+/+}$ and ${ }^{-/-}$mice littermates displayed any statistically significant differences in body weight up to an age of 38 weeks when fed on a regular chow diet (see Supplementary material in the online version of the Journal of Moleculer Endocrinology at http://jme.endocrinology-journals.org/content/vol42/issue3/).

\section{Lack of a bone phenotype in GPRC6A knockout mice}

To evaluate the bone structural histology, tibias from wild-type and GPRC6A knockout male and female mice were compared by $3 \mathrm{D}$ analysis using $\mu \mathrm{CT}$. No differences in bone architecture were observed between genotypes when comparing groups of either ten male or ten female wild-type and knockout mice, i.e. no statistically significant differences in trabecular bone volume (BV/TV), trabecular number, separation or thickness (Table 1). A representative 3D construction of a scan is shown in Fig. 2. In keeping with these negative 
Table 1 Bone measurements of 13-week-old GPRC6A ${ }^{+/+},{ }^{+/-}$, and ${ }^{-/-}$mice

Males

\section{Bone parameters ${ }^{a}$}

Bone structure (tibia) BV/TV (\%)

Trabecular number $(1 / \mathrm{mm})$

Trabecular separation $(\mu \mathrm{m})$

Trabecular thickness $(\mu \mathrm{m})$

Bone biomarkers

OCN (ng/ml)

D-Pyr/creatinine $((\mathrm{nmol} / \mathrm{l}) /(\mathrm{mmol} / \mathrm{l}))$

$$
+/+
$$

$8 \cdot 4 \pm 1 \cdot 2$
$3 \cdot 1 \pm 0 \cdot 3$
$418 \pm 46$
$25 \cdot 4 \pm 1 \cdot 4$
$41 \cdot 2 \pm 3 \cdot 2$
$16 \cdot 0 \pm 3 \cdot 3$

$\begin{array}{ll}8 \cdot 9 \pm 0 \cdot 9 & 9 \cdot 3 \pm 0 \cdot 9 \\ 3 \cdot 3 \pm 0 \cdot 2 & 3 \cdot 3 \pm 0 \cdot 3 \\ 388 \pm 56 & 375 \pm 54 \\ 25 \cdot 7 \pm 1 \cdot 1 & 27 \cdot 3 \pm 1 \cdot 4 \\ & \\ 46 \cdot 0 \pm 2 \cdot 8 & 40 \cdot 6 \pm 4 \cdot 0 \\ 12 \cdot 7 \pm 1 \cdot 8 & 15 \cdot 9 \pm 2 \cdot 0\end{array}$

Females

$+1+\quad+1-\quad \underline{-1-}$

$5 \cdot 1 \pm 0 \cdot 3$

$2 \cdot 1 \pm 0 \cdot 11$

$626 \pm 43$

$22 \cdot 9 \pm 0 \cdot 8$

$57 \cdot 3 \pm 4 \cdot 0$ $20 \cdot 3 \pm 2 \cdot 1$

No statistical difference between genotypes was found. BV, bone volume; TV, total volume; OCN, osteocalcin and D-Pyr, urinary deoxypyridinoline cross-link level.

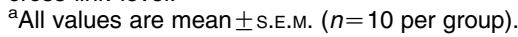

structural data, osteoclast, osteoblast, and dynamic parameters were consequently not investigated. Analysis of BMD, by means of pQCT, revealed no changes in trabecular, cortical or total metaphyseal $\mathrm{BMD}$, or cortical diaphysis BMD, in knockout mice compared with wild-type littermates (Fig. 3). Thus, the $\mathrm{BMD}$ data are in concordance with the $3 \mathrm{D} \mu \mathrm{CT}$ dataset, since no cellular activity has been observed in regards to resorptive and formative biomarkers. Finally, we

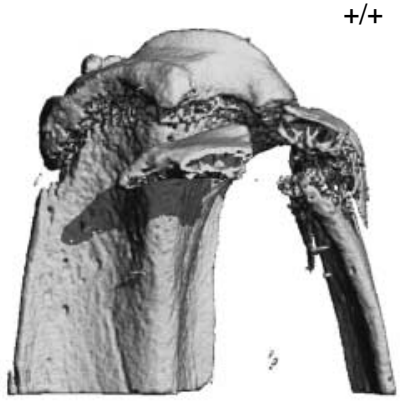

$1000 \mu \mathrm{m}$

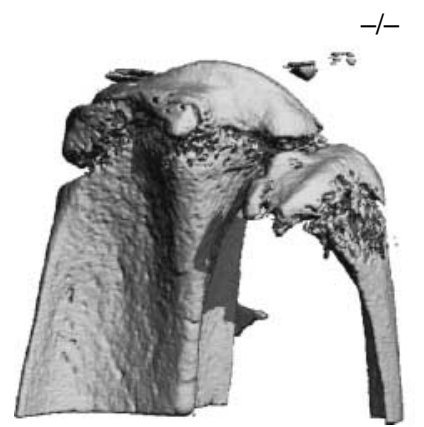

$1000 \mu \mathrm{m}$
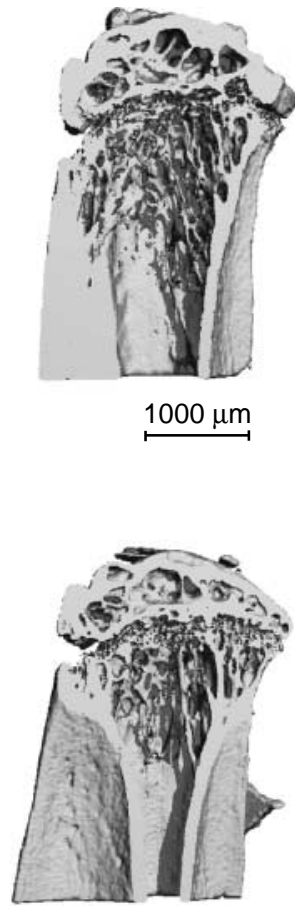

$1000 \mu \mathrm{m}$

Figure 2 Three-dimensional reconstructed trabecular bone images from $\mu \mathrm{CT}$ scans. Illustrative $3 \mathrm{D}$ images of the proximal tibias from 13-week-old GPRC6A wild-type and knockout mice at $9 \mu \mathrm{M}$ resolution. Left, surface view and right, open view. searched for possible alterations in cellular activity, by measuring the bone biomarkers osteocalcin in serum and deoxypyridoniline (D-Pyr) in urine, relevant in relation to bone formation and resorption respectively. Again, we observed no influence of the elimination of GPRC6A gene products on the measured values (Table 1). Data obtained from our wild-type littermates are in the same range as C57BL/6 wild-type (Clément-Lacroix et al. 2005, Morvan et al. 2006).

\section{Discussion}

From the present study, we have obtained no data to support a role for GPRC6A in bone homeostasis under normal physiological conditions in mice. Furthermore, we have been unable to demonstrate any changes relating to bone structure or bone turnover between 13-week-old GPRC6A wild-type and knockout mice. These findings correlate with the lack of differences in body weight between male and female wild-type and knockout mice up to 38 weeks of age. Based on the expression of mGPRC6A in long bone and its concerted $\mathrm{Ca}^{2+}$ /amino acid signaling, as shown by several groups (Pi et al. 2005, Breitwieser 2008, Conigrave et al. 2008), the apparent absence of a phenotype related to bone physiology in the knockout mice might be ascribed to several factors. As always with knockout animals, there is an inherent possibility that compensatory mechanisms have offset the impact of the elimination of the gene (Zambrowicz \& Sands 2003). Similarly, in the current scenario, it could be imagined that a protein or mechanism implicated in bone calcium sensing could substitute for the lack of GPRC6A. Given the common gene ontology and ligand preferences of $\mathrm{CaR}$ and GPRC6A, CaR is an obvious candidate in this respect, notwithstanding current controversies in the field. Whereas it is well established that CaR plays an essential role in calcium homeostasis of the organism through 
Trabecular metaphysis BMD

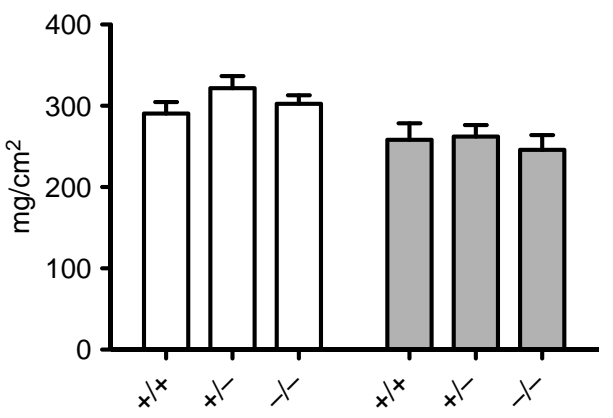

Total metaphysis BMD

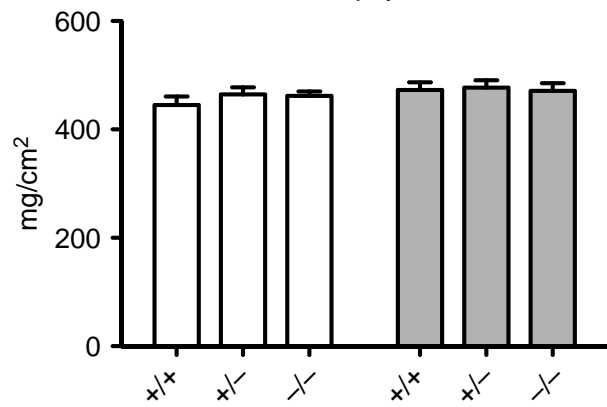

Cortical metaphysis BMD

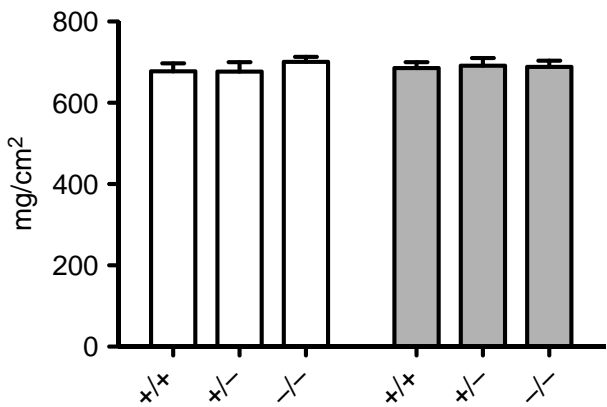

Cortical diaphysis BMD

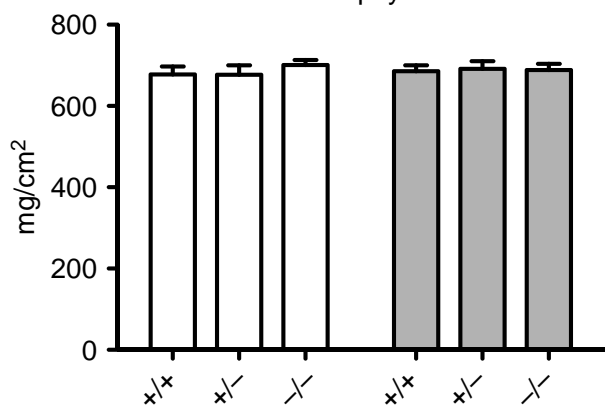

Figure 3 Bone mineral density (BMD) measurements in $\mathrm{GPRC} \mathrm{A}^{+/+},{ }^{+/-}$, and ${ }^{-1-}$ mice. Trabecular, cortical, and total BMD values in the metaphysial tibia and cortical BMD values in the diaphysial tibia by pQCT. Values are means \pm S.E.M. ( $n=5-11$ per group). No statistical significance was found between either wild-type and knockout males (open bars) or females (gray bars).

sensing and maintaining the extracellular calcium concentration, and by regulating hormone secretion in the parathyroid gland and kidneys, its role in bone is debated (Tfelt-Hansen \& Brown 2005). Despite reports showing a lack of expression and function of CaR in bone (Pi et al. 1999, Kos et al. 2003, Tu et al. 2003, Pi \& Quarles 2004, 2005), several groups have provided substantial evidence for the expression and function of the native receptor and a functional splice variant both at mRNA and protein level in bone, osteoblasts, osteoclasts, and calvaria (Chang et al. 1999, Chattopadhyay et al. 2004, 2007, Dvorak et al. 2004, Rodriguez et al. 2005, Mentaverri et al. 2006). Furthermore, a conditional osteoblast-specific CaR knockout mouse has recently been found to exhibit abnormalities in bone development (Chang et al. 2008). Accordingly, it would be interesting to generate a bone-specific conditional GPRC6A or a GPRC6A/CaR double knockout mouse, something which is of special pertinence to us given the already engineered Gprc6a conditional allele in ES cells.

When interpreting the current data, it is important to keep in mind that the role of GPRC6A in bone physiology was evaluated for just one age of mice (13-week-old) and in a normal physiological setting.
Although any clear effects on bone development or homeostasis would likely appear at this age, it cannot be ruled out that involvement of GPRC6A on bone development and/or homeostasis is age or strain dependent. For example, a transitory bone phenotype has been reported in young mice during growth (i.e. GH receptor knockout mice; Sims et al. 2000) and appearance of a bone phenotype has been reported in mice of old age (i.e. $\Delta$ fosB knockout mice; Sims et al. 2002). Furthermore, it could be speculated that the emergence of a bone phenotype in the GPRC6A knockout mice requires a pathophysiological condition, such as a disease-induced state or a calcium depleted/overloaded state. Scenarios including receptor overstimulation (achieved by prolonged amino acid $/ \mathrm{Ca}^{2+}$ ingestion), or ovariectomy leading to bone loss, may be imagined to completely determine the role of GPRC6A in bone physiology.

In conclusion, we have generated specific GPRC6A knockout mice and here for the first time report that the mice are viable, display no body weight differences compared with wild-type littermates, and lack a phenotype in relation to normal bone physiology. As mentioned previously, the broad ligand recognition and expression of GPRC6A has led to several 
hypotheses on the physiological function of the receptor such as a metabolic sensor, a role in taste or neurotransmission or an implication in cell death (Civelli 2005, Wellendorph et al. 2005, Conigrave \& Hampson 2006, Bräuner-Osborne et al. 2007). Owing to the present lack of selective agonists and antagonists, our generation of a GPRC6A knockout mouse represents an important new tool, which we are currently employing to investigate the other suggested physiological function(s) of the receptor.

\section{Declaration of interest}

The authors declare that there is no conflict of interest that would prejudice the impartiality of this scientific work.

\section{Funding}

This work was supported by the Swiss Science Foundation (Grant 3100-67100.01 to BB), the Danish Medical Research Council, the Novo Nordisk Foundation, Simon Fougner Hartmanns Familiefond, Aase og Ejnar Danielsens Fond, Beckett-Fonden, Savværksejer Jeppe Juhl og hustru Ovita Juhls Mindelegat, the Lundbeck Foundation and the Drug Research Academy.

\section{Acknowledgements}

We thank Daniela Nebenius-Oosthuizen from the Transgenic Mouse Core Facility at the University of Basel for blastocyst injections.

\section{References}

Bjarnadóttir TK, Fredriksson R \& Schiöth HB 2005 The gene repertoire and the common evolutionary history of glutamate, pheromone (V2R), taste(1) and other related G protein-coupled receptors. Gene 362 70-84.

Bräuner-Osborne H, Wellendorph P \& Jensen AA 2007 Structure, pharmacology and therapeutic prospects of family C G-protein coupled receptors. Current Drug Targets 8 169-184.

Breitwieser GE 2008 Extracellular calcium as an integrator of tissue function. International Journal of Biochemistry and Cell Biology $\mathbf{4 0}$ $1467-1480$.

Chang W, Tu C, Chen T-H, Komuves L, Oda Y, Pratt SA, Miller S \& Shoback D 1999 Expression and signal transduction of calcium-sensing receptors in cartilage and bone. Endocrinology 140 5883-5893.

Chang W, Tu C, Chen T-H, Bikle D \& Shoback D 2008 The extracellular calcium-sensing receptor (CaSR) is a critical modulator of skeletal development. Science Signaling 1 ral.

Chattopadhyay N, Yano S, Tfelt-Hansen J, Rooney P, Kanuparthi D, Bandyopadhyay S, Ren X, Terwilliger E \& Brown EM 2004 Mitogenic action of calcium-sensing receptor on rat calvarial osteoblasts. Endocrinology 145 3451-3462.

Chattopadhyay N, Quinn SJ, Kifor O, Ye C \& Brown EM 2007 The calcium-sensing receptor $(\mathrm{CaR})$ is involved in strontium ranelate-induced osteoblast proliferation. Biochemical Pharmacology 74 438-447.

Chikatsu N, Fukumoto S, Takeuchi Y, Suzawa M, Obara T, Matsumoto T \& Fujita T 2000 Cloning and characterization of two promoters for the human calcium-sensing receptor (CaSR) and changes of CaSR expression in parathyroid adenomas. Journal of Biological Chemistry 275 7553-7557.

Christiansen B, Wellendorph P \& Bräuner-Osborne H $2006 a$ Activity of $\mathrm{L}-\alpha$-amino acids at the promiscuous goldfish odorant receptor 5.24. European Journal of Pharmacology 536 98-101.

Christiansen B, Wellendorph P \& Bräuner-Osborne H $2006 b$ Known regulators of nitric oxide synthase and arginase are agonists at the human G-protein-coupled receptor GPRC6A. British Journal of Pharmacology 147 855-863.

Christiansen B, Hansen KB, Wellendorph P \& Bräuner-Osborne H 2007 Pharmacological characterization of mouse GPRC6A, an L- $\alpha-$ amino-acid receptor modulated by divalent cations. British Journal of Pharmacology 150 798-807.

Civelli O 2005 An orphan receptor adopted by a family of transmitters. Molecular Pharmacology 67 583-584.

Clément-Lacroix P, Sims NA, Da Ponte F, Bouali Y, Binart N, Moriggl R, Goffin V, Coschigano K, Gaillard-Kelly M, Kopchick J et al. 2000 Bone homeostasis in growth hormone receptor-null mice is restored by IGF-I but independent of Stat5. Journal of Clinical Investigation 106 1095-1103.

Clément-Lacroix P, Ai M, Morvan F, Roman-Roman S, Vayssiere B, Belleville C, Estrera K, Warman ML, Baron R \& Rawadi G 2005 Lrp5-independent activation of Wnt signaling by lithium chloride increases bone formation and bone mass in mice. PNAS 102 17406-17411.

Conigrave AD \& Hampson DR 2006 Broad-spectrum L-amino acid sensing by class 3 G-protein-coupled receptors. Trends in Endocrinology and Metabolism 17 398-407.

Conigrave AD, Quinn SJ \& Brown EM 2000 L-Amino acid sensing by the extracellular $\mathrm{Ca}^{2+}$-sensing receptor. PNAS 97 4814-4819.

Conigrave AD, Brown EM \& Rizzoli R 2008 Dietary protein and bone health: roles of amino acid-sensing receptors in the control of calcium metabolism and bone homeostasis. Annual Review of Nutrition 28 131-155.

Dvorak MM \& Riccardi D $2004 \mathrm{Ca}^{2+}$ as an extracellular signal in bone. Cell Calcium 35 249-255.

Dvorak MM, Siddiqua A, Ward DT, Carter DH, Dallas SL, Nemeth EF \& Riccardi D 2004 Physiological changes in extracellular calcium concentration directly control osteoblast function in the absence of calciotropic hormones. PNAS 101 5140-5145.

Francesconi A \& Duvoisin RM 2004 Divalent cations modulate the activity of metabotropic glutamate receptors. Journal of Neuroscience Research 75 472-479.

Galvez T, Urwyler S, Prézeau L, Mosbacher J, Joly C, Malitschek B, Heid J, Brabet I, Froestl W, Bettler B et al. $2000 \mathrm{Ca}^{2+}$ requirement for high-affinity $\gamma$-aminobutyric acid (GABA) binding at $\mathrm{GABA}_{\mathrm{B}}$ receptors: involvement of serine 269 of the $\mathrm{GABA}_{\mathrm{B}} \mathrm{R} 1$ subunit. Molecular Pharmacology 57 419-426.

Harno E, Edwards G, Geraghty AR, Ward DT, Dodd RH, Dauban P, Faure H, Ruat M \& Weston AH 2008 Evidence for the presence of GPRC6A receptors in rat mesenteric arteries. Cell Calcium 44 210-219.

Kapadia RD, Stroup GB, Badger AM, Koller B, Levin JM, Coatney RW, Dodds RA, Liang X, Lark MW \& Gowen M 1998 Applications of micro-CT and MR microscopy to study pre-clinical models of osteoporosis and osteoarthritis. Technology and Health Care 6 361-372.

Kilby NJ, Snaith MR \& Murray JA 1993 Site-specific recombinases: tools for genome engineering. Trends in Genetics 9 413-421.

Kos CH, Karaplis AC, Peng JB, Hediger MA, Goltzman D, Mohammad KS, Guise TA \& Pollak MR 2003 The calcium-sensing receptor is required for normal calcium homeostasis independent of parathyroid hormone. Journal of Clinical Investigation 111 1021-1028.

Kuang D, Yao Y, Lam J, Tsushima RG \& Hampson DR 2005 Cloning and characterization of a family $\mathrm{C}$ orphan G-protein coupled receptor. Journal of Neurochemistry 93 383-391. 
Kuang D, Yao Y, Maclean D, Wang M, Hampson DR \& Chang BS 2006 Ancestral reconstruction of the ligand-binding pocket of Family C G protein-coupled receptors. PNAS 103 14050-14055.

Kubo Y, Miyashita T \& Murata Y 1998 Structural basis for a $\mathrm{Ca}^{2+}$. sensing function of the metabotropic glutamate receptors. Science 279 1722-1725.

Kwan KM 2002 Conditional alleles in mice: practical considerations for tissue-specific knockouts. Genesis 32 49-62.

Mentaverri R, Yano S, Chattopadhyay N, Petit L, Kifor O, Kamel S, Terwilliger EF, Brazier M \& Brown EM 2006 The calcium sensing receptor is directly involved in both osteoclast differentiation and apoptosis. FASEB Journal 20 2562-2564.

Mitsuma T, Rhue N, Kayama M, Mori Y, Adachi K, Yokoi Y, Ping J, Nogimori T \& Hirooka Y 1999 Distribution of calcium sensing receptor in rats: an immunohistochemical study. Endocrine Regulations 33 55-59.

Morvan F, Boulukos K, Clément-Lacroix P, Roman Roman S, SucRoyer I, Vayssiere B, Ammann P, Martin P, Pinho S, Pognonec P et al. 2006 Deletion of a single allele of the $D k k 1$ gene leads to an increase in bone formation and bone mass. Journal of Bone and Mineral Research 21 934-945.

Pi M \& Quarles LD 2004 A novel cation-sensing mechanism in osteoblasts is a molecular target for strontium. Journal of Bone and Mineral Research 19 862-869.

Pi M \& Quarles LD 2005 Osteoblast calcium-sensing receptor has characteristics of ANF / 7TM receptors. Journal of Cellular Biochemistry 95 1081-1092.

Pi M, Hinson TK \& Quarles L 1999 Failure to detect the extracellular calcium-sensing receptor (CasR) in human osteoblast cell lines. Journal of Bone and Mineral Research 14 1310-1319.

Pi M, Faber P, Ekema G, Jackson PD, Ting A, Wang N, Fontilla-Poole M, Mays RW, Brunden KR, Harrington JJ et al. 2005 Identification of a novel extracellular cation-sensing G-protein-coupled receptor. Journal of Biological Chemistry 280 40201-40209.

Pin J-P, Galvez T \& Prézeau L 2003 Evolution, structure, and activation mechanism of family 3 /C G-protein-coupled receptors. Pharmacology and Therapeutics 98 325-354.

Pin J-P, Kniazeff J, Goudet C, Bessis AS, Liu J, Galvez T, Acher F, Rondard P \& Prézeau L 2004 The activation mechanism of class-C G-protein coupled receptors. Biology of the Cell 96 335-342.

Regard JB, Kataoka H, Cano DA, Camerer E, Yin L, Zheng Y-W, Scanlan TS, Hebrok M \& Coughlin SR 2007 Probing cell typespecific functions of $\mathrm{G}_{\mathrm{i}}$ in vivo identifies GPCR regulators of insulin secretion. Journal of Clinical Investigation 117 4034-4043.

Rodriguez L, Tu C, Cheng Z, Chen T-H, Bikle D, Shoback D \& Chang W 2005 Expression and functional assessment of an alternatively spliced extracellular $\mathrm{Ca}^{2+}$-sensing receptor in growth plate chondrocytes. Endocrinology 146 5294-5303.

Rüegsegger P, Koller B \& Müller R 1996 A microtomographic system for the nondestructive evaluation of bone architecture. Calcified Tissue International 58 24-29.

Saunders R, Nahorski SR \& Challiss RA 1998 A modulatory effect of extracellular $\mathrm{Ca}^{2+}$ on type la metabotropic glutamate receptormediated signalling. Neuropharmacology 37 273-276.
Schwenk F, Baron U \& Rajewsky K 1995 A cre-transgenic mouse strain for the ubiquitous deletion of loxP-flanked gene segments including deletion in germ cells. Nucleic Acids Research 23 5080-5081.

Silve C, Petrel C, Leroy C, Bruel H, Mallet E, Rognan D \& Ruat M 2005 Delineating a $\mathrm{Ca}^{2+}$ binding pocket within the venus flytrap module of the human calcium-sensing receptor. Journal of Biological Chemistry 280 37917-37923.

Sims NA, Clément-Lacroix P, Da Ponte F, Bouali Y, Binart N, Moriggl R, Goffin V, Coschigano K, Gaillard-Kelly M, Kopchick J et al. 2000 Bone homeostasis in growth hormone receptor-null mice is restored by IGF-I but independent of Stat5. Journal of Clinical Investigation 106 1095-1103.

Sims NA, Sabatakos G, Chen JS, Kelz MB, Nestler EJ \& Baron R 2002 Regulating $\Delta$ FosB expression in adult Tet-Off- $\Delta$ FosB transgenic mice alters bone formation and bone mass. Bone 30 32-39.

Sims NA, Clément-Lacroix P, Minet D, Fraslon-Vanhulle C, GaillardKelly M, Resche-Rigon M \& Baron R 2003 A functional androgen receptor is not sufficient to allow estradiol to protect bone after gonadectomy in estradiol receptor-deficient mice. Journal of Clinical Investigation 111 1319-1327.

Teitelbaum SL 2000 Bone resorption by osteoclasts. Science 289 1504-1508.

Tfelt-Hansen J \& Brown EM 2005 The calcium-sensing receptor in normal physiology and pathophysiology: a review. Critical Reviews in Clinical Laboratory Sciences 42 35-70.

Tronche F, Casanova E, Turiault M, Sahly I \& Kellendonk C 2002 When reverse genetics meets physiology: the use of site-specific recombinases in mice. FEBS Letters 529 116-121.

Tu Q, Pi M, Karsenty G, Simpson L, Liu S \& Quarles LD 2003 Rescue of the skeletal phenotype in CasR-deficient mice by transfer onto the Gcm2null background. Journal of Clinical Investigation 111 1029-1037.

Wellendorph P \& Bräuner-Osborne H 2004 Molecular cloning, expression, and sequence analysis of GPRC6A, a novel family $\mathrm{C}$ G-protein coupled receptor. Gene 335 37-46.

Wellendorph P, Hansen KB, Balsgaard A, Greenwood JR, Egebjerg J \& Bräuner-Osborne H 2005 Deorphanization of GPRC6A: a promiscuous $\mathrm{L}-\alpha$-amino acid receptor with preference for basic amino acids. Molecular Pharmacology 67 589-597.

Wellendorph P, Burhenne N, Christiansen B, Walter B, Schmale H \& Bräuner-Osborne H 2007 The rat GPRC6A: cloning and characterization. Gene 396 257-267.

Wise A, Green A, Main MJ, Wilson R, Fraser N \& Marshall FH 1999 Calcium sensing properties of the $\mathrm{GABA}_{\mathrm{B}}$ receptor. Neuropharmacology 38 1647-1656.

Zambrowicz BP \& Sands AT 2003 Knockouts model the 100 best-selling drugs - will they model the next 100? Nature Reviews. Drug Discovery 2 $38-51$.

Zhang Z, Qiu W, Quinn SJ, Conigrave AD, Brown EM \& Bai M 2002 Three adjacent serines in the extracellular domains of the CaR are required for L-amino acid-mediated potentiation of receptor function. Journal of Biological Chemistry 277 33727-33735.

Received in final form 2 December 2008 Accepted 22 December 2008

Made available online as an Accepted Preprint 22 December 2008 